\title{
Shaping Public Space, in Public, with the Public: Co-Drawing the Continuous Campus
}

\author{
ANTJE STEINMULLER \\ California College of the Arts \\ CHRISTOPHER FALLIERS \\ California College of the Arts
}

Protocols of public space production have been evolving in recent years, with the public no longer solely the end user of an architect-designed space. The form of public space as the domain of architects is increasingly replaced by a need to structure a process of formation - a forum that positions architects as collaborators with the public, designing sites, artifacts, and protocols for citizen engagement. This paper puts forward an engaged methodology for public space formation that operates in public and with the public, and employs collaborative drawing.

The proposed methodology draws from two spheres of influence - relational art and design activism. In his book Relational Aesthetics [1998], Nicolas Bourriaud identifies art practices that position the artist/artwork as the 'catalyst of exchange' or 'producer of an encounter', with outcomes taking the form of lived social environments. Catalyzing collaborations between people in places of gathering, such works put on display the human interactions they engender. The second sphere is rooted in design practices merging design advocacy and activism with short-term catalytic interventions. Built on Lefebvre's understanding that space is inherently a social product, such projects are often designed as a process of learning not determined by professional hierarchies and norms, but through the collective acquisition and sharing of knowledge through public engagement.

Introducing a teaching methodology that develops collective knowledge through public forums around codrawing, this paper examines two experiments in which architects (and architecture students respectively) acted as an itinerant, engaged think tank together with a specific community. Re-situated into the commons, such forums present platforms for public engagement (an artifact), structures for stimulating public dialog (a protocol), and the choreography of public gatherings (an event). One of the experiments, designed for ACSA Stanford, put forward a session in which conference participants co-drew "the continuous campus," building hands-on knowledge of public space production (the campus) in public (on the campus), with the public (the users of the campus).

\begin{abstract}
"From within a hard shell swells the soft bubble, a billowing urban room hatched in the back of a delivery van. This genie in a lamp makes for instant theater, and shows how wind in a bag can make instant architecture. But this is no ordinary pop-up circus tent. Rather than being consumed as entertainment, like a circus act or the dead matter of architecture, Spacebuster consumes its viewers, and they in turn transform it." ${ }^{11}$
\end{abstract}

-Gideon Fink Shapiro, "Spacebusting"

\section{PRODUCING PUBLIC SPACE}

Protocols of public space production have been evolving in recent years, with the public no longer solely the end user of an architect-designed space. Raumlabor's Spacebuster, described by Shapiro in the quote above, is one in growing number of urban space activation projects that combine tactics for citizen initiative, collaborative formation, and shared stewardship into what can best be described as a contemporary 'commons'. This type of 'public space-as-commons' involves members of the public in a process of rediscovery, and re-appropriation, of urban space according to their needs and desires. The form of public space as the domain of architects is increasingly replaced by a need to structure and accompany a process of formation- a forum that positions architects as collaborators with the public, designing sites, artifacts, and protocols for citizen engagement. This paper puts forward an engaged teaching methodology for public space formation that operates in public and with the public. It leverages public space as a classroom within which architecture students develop and practice inclusive protocols for shaping new urban commons, and as a site in which architects engage a local public in the collaborative development of spatial ideas.

\section{RELATIONAL ART MEETS DESIGN ACTIVISM}

The evolution of such protocols draws from two spheres of influence. In his book Relational Aesthetics [1998], Nicolas Bourriaud identifies art practices that position the artist as the 'catalyst of exchange' or 'production of an encounter', with outcomes that often take the form of lived social environments. Emerging at a time when social relationships are increasingly predictable and commercialized ${ }^{2}$, Bourriaud highlights artistic production that takes the form of meetings, encounters, events, various types of collaboration between 

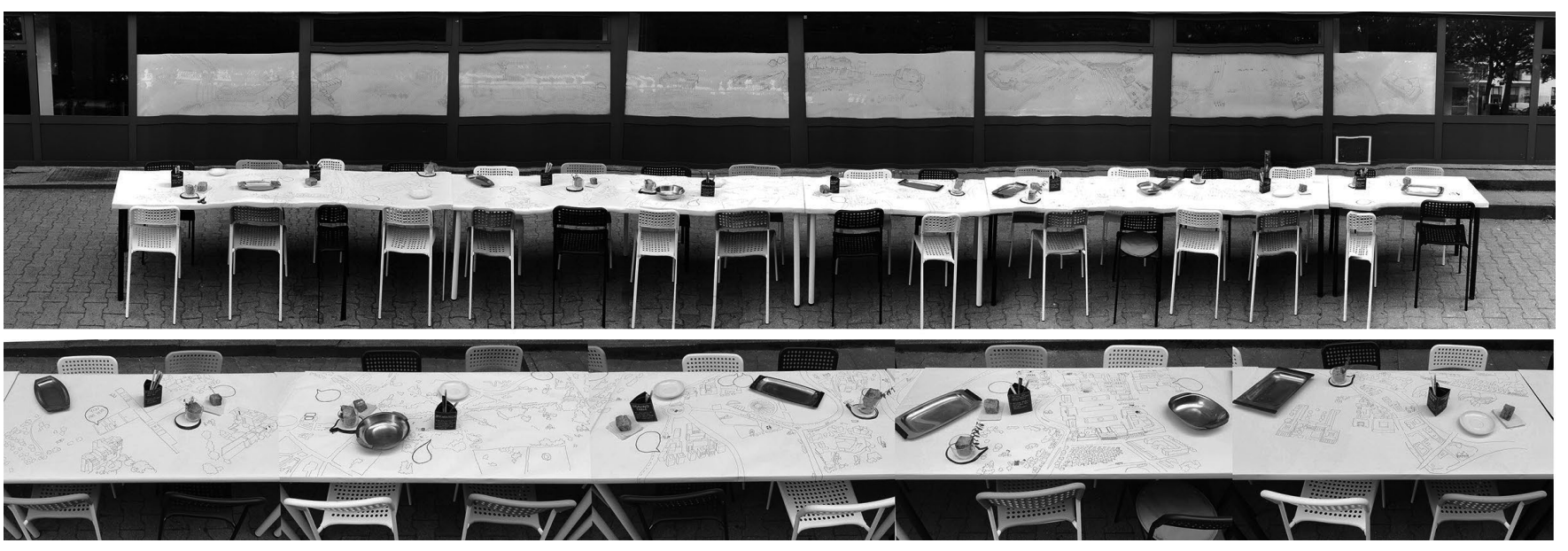

Figure 1. "Drawing Table" artifact, Berlin Hafenplatz (photos/collage: Antje Steinmuller)

people and places of gathering On display as the aesthetic 'object/subject' are the human interactions they engender ${ }^{3}$. Rikrit Tiravanja's 1992 Thai dinner inside 303 Gallery in New York employ a combination of a kitchen environment and the social protocols of cooking and dinner to catalyze/display familial interactions between gallery visitors. Futurefarmers' Ethnobotanical Station employs a combination of artifacts (a mobile cart, map, and information gathering equipment) and workshops (joint information gathering and discussion) as a platform to engender the interaction of people with their environment and to catalyze collective knowledge building/sharing on relationships between humans and the environment. The mobile artifact allows for flexible engagement and accumulation of knowledge gathering with different locations, people, and over time. The unfolded cart acts as both attractor and visual display, inside or outside a gallery setting. Beyond examples relying on the presence of the artist as actor/catalyst for interaction, Candy Chang's "I Wish This Was" project places artifacts into urban space in order to invite and record citizens' response. Exploring the process of civic engagement in shaping their neighborhoods beyond the limitations of community meetings, Chang posts a designed composition of stickers in empty storefronts and abandoned urban spaces, transforming the urban surface into an invitation for residents to share their desires for these locations. While not focused on direct social interaction, the work acts as kiosk, triggering a play of ideas and collective communication as residents comment on the notes of others over time. Using the designed artifact and/or action positioned in public, these projects act as catalysts for social exchange. They exist in public to be played out by the public.

The second sphere of influence is rooted in design practices that merge design advocacy and activism with short-term catalytic interventions. Jeremy Till's term "spatial agency" takes as its basis Lefebvre's argument that space is inherently a social product, ${ }^{4}$ a condition produced collectively, inherently dynamic, unfinished, and continually changing over time - by and with the involvement of changing actors. ${ }^{5}$ Spatial agency, here, is framed as an act of transformation, engaging and negotiating a given (spatial) condition with intent. Till adopts Anthony Gidden's notion of "acting otherwise" ${ }^{6}$, acting with willingness to leave behind the boundaries of established knowledge, as a prerequisite to a process of learning that is not determined by hierarchy and professional norms. This process opens the door to collectively acquiring knowledge through engagement within a world in which everyone holds specific 'expert knowledge'?

This engaged, social production of space can be found in Archigram's 1969 Instant City protocols. Rendered (and symbolized) as a floating airship equipped with technology and props, the act of design is that of an embodied catalytic agent that instigates community engagement, interaction, and education through designed temporary events, leaving behind an altered collective infrastructure for future, more durable social interactions. Arguably a micro-version of an instant city, Santiago Cirugeda's Urban Recipes widely distributes instructions to deploy small 'architectures' (dumpsters and other elements affordable and accessible to everyone) as a means for citizens to appropriate, occupy, and activate urban space within their neighborhood. In Cirugeda's project Taking the Street, detailed DIY instructions empower residents to apply for a dumpster permit, equip the dumpster space with other micro-architectures, and create spaces for socializing and play. Cirugeda leverages conventional mechanisms of city code towards the bottom-up initiation of urban respites to catalyze social activity. Translating Instant City's envisioned long-term effects into recent planning for Tempelhof Airfield in Berlin, the collective Raumlabor defined so-called Pioneer Fields on an emerging open space site where citizens could initiate, build, and host a range of activities and events during

a three-year period. Thought of as a site for testing, learning, and acknowledging local residents as 'experts', these temporary pioneer uses on the airfield were meant to leave behind 

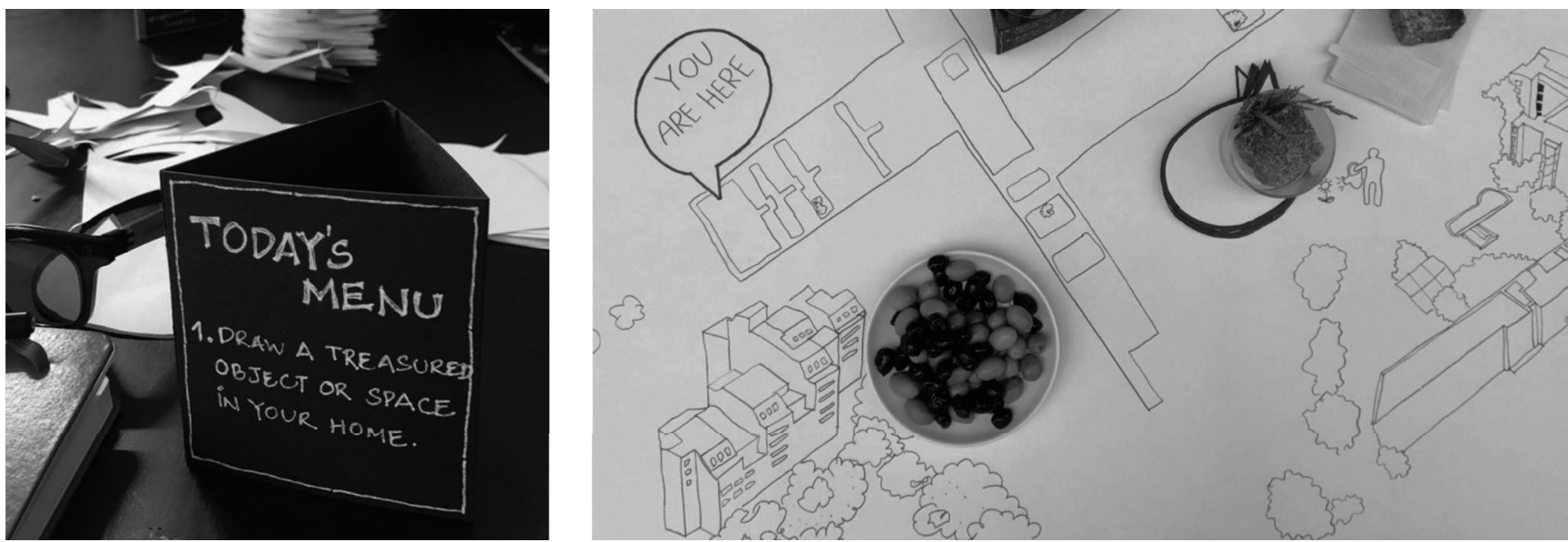

Figure 2. Menu cards as protocol for collaborative drawing (left), speech bubble note cards on the drawing table (right); (photos: Antje Steinmuller)

lessons for what might be suitable and desirable programs to be evolved longer-term. Beyond the design of catalytic mechanisms like Cirugeda's DYI instructions or Raumlabor's Pioneer Field process, spatial designers today have also taken on the role of designer and cultural manager of urban space, perhaps best embodied by Envelope A+D's PROXY SF, a site for temporary and long-term food businesses, retail, and cultural events. Beyond the transformation of a vacant urban parcel with a changing array of adaptable shipping containers, Envelope $A+D$ committed their own financial investment to initiate the project, designed responsive programming with neighborhood leaders, sponsors changing public art, and runs the long-term management. In these projects, design tactics for the production of public space expand beyond standard practice and the design of form. The involve architects embedding themselves within a community, the design of processes for local involvement, and the initiation of dynamic and evolving form and programming.

\section{COMPONENTS OF A FORUM FOR PUBLIC DIALOG}

Acknowledging that most public space projects require months if not years of work and dialog, we have developed a teaching methodology that leverages the format of intensive multi-week travel studios to plug into ongoing public space or commons projects, and partner with local collective/ designer/architects and community non-profits. This allows the studio to act as an itinerant, engaged think tank for the development of short-term catalytic interventions. The classroom, class structure, and class outcomes are altered. The classroom, in this case, is replaced by the city, with workspace embedded as a short-term residency in or near the space we work on. Students experience the space and community on a daily basis. The local community becomes an integral part of the classroom, with an introduction facilitated by local collaborators. The class structure, correspondingly, is changed from a seminar or studio about the place, to a workshop with residents and within the site itself. Examples have included an emerging community garden and a vacant storefront as sites of latent social/spatial potential. Rather than designing a fixed vision for the space, design tasks are three-fold, combining the design of a platform for public engagement (the artifact), the structure of a dialog with the public defining how knowledge is built collaboratively (the protocol), and the choreography of gatherings that directly catalyze interaction and conversation with and between residents (the event).

Drawing on the above spheres of influence, the artifact is critical to the process. Aimed at creating an environment for conversation, the production of an artifact can be approached as building a space for dialog (as in Raumlabor's Spacebuster), and/or an object that provokes interaction and discussion (as in Futurefarmers' Ethnobotanical Station). The design of the artifact most clearly asks students to leverage conventional architectural expert knowledge. The development of a protocol challenges students to "act otherwise" (per Giddens), moving beyond their typical skill-sets as designers, and drawing on local social conventions to facilitate and structure social interactions (Tiravanja's Thai Food dinner), initiate action (Cirugeda's DIY instructions), and prompt dialog between others (like Candy Chang's "I Wish This Was" stickers). Lastly, the development of events necessitates thinking through temporal processes and possible scenarios, the need for presence of the designer (Futurefarmers' Ethnobiological Station workshops) vs. the production of a framework within which others guide events (Raumlabor's Pioneer Fields), as well as means of documenting the knowledge gathered. Ideally, the event aims to be transformative, leaving behind altered environments or instigating future action (Archigram's Instant City).

\section{PRACTICE: LEARNING TO BE A CATALYST}

The following paragraphs discuss two applications of this methodology with variations in the manifestation of artifact, protocol, and event. ${ }^{8}$ The first test case was developed with students from California College of the Arts, the architecture 


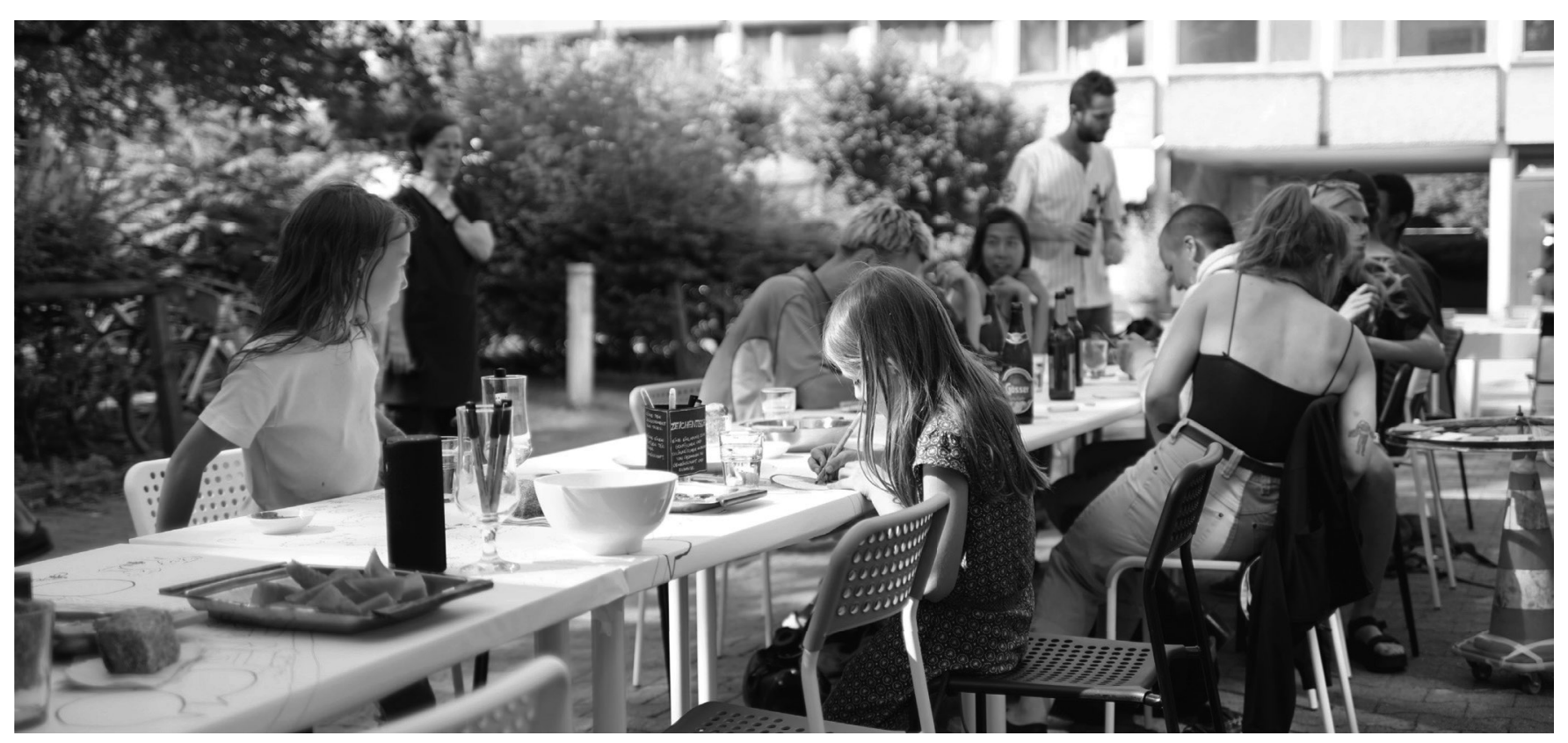

Figure 3: "Drawing Table" event, Berlin Hafenplatz, June 2018 (photo: Zhongwei Wang)

collective Raumlabor, and the citizens of Berlin, while the second case, developed by the authors, took place with ACSA conference attendees on the Stanford campus. Both case studies share prior research on the respective sites, grounding the work in their history, typology, spatial parameters, and use patterns.

The Berlin test case was set up as an intensive summer travel studio on contemporary public space production. Collaboratively guided with Raumlabor, the class joined the early stages of working with a community to revitalze the neglected open space and common areas around an extralarge housing development project called Hafenplatz. The developer had hired Raumlabor to devise ways of engaging local citizens in conversation about the future of the neighborhood. The Hafenplatz site became the classroom for the studio which operated as a mobile think tank out of the empty space of a former supermarket in the 1970s housing complex soon to be redeveloped.

A central location to the neighborhood, the storefront of this supermarket became the backdrop and canvas for a collective drawing/dinner event, titled "Drawing Table / Zeichentisch". As the central artifact for this event, the students developed a 30-foot co-drawing table (Fig. 1) that held axonometric and perspectival drawings of the city, beginning with the local Hafenplatz site, adjacent neighborhoods, and the larger city context. The drawings on the table. were paralleled by a similar sequence of drawings mounted to the inside of the storefront windows, offering the glass surface as a secondary canvas. To engage citizens in conversation about the site, students developed drawing and talking prompts that were placed as 'menu cards' on the table (Fig.2, left). These prompts posed questions about places of community and identity in the neighborhood, providing a protocol for engaging with the drawings on the table. The overall co-drawing event was designed as a neighborhood dinner with food and drinks provided on the drawing table, creating an informal atmosphere of 'napkin drawings' on a paper tablecloth (Fig. 3).

In order to be able to entice an audience of non-architects to communicate through drawing, several steps were taken in the design of the overall framework for the event. The choice of axonometric/perspectival base drawings was critical to provide easily legible base drawings (Fig. 4). To lower the threshold of adding to the drawing, note cards in the form of cartoon speech bubbles were distributed on the table to people to draw and write on (Fig.2, right). Students engaged in direct conversation with participants either individually, or in small groups around the table. If participants chose speech bubbles over drawing directly onto the table, students were available to 'translate' these into drawings on the storefront window surface. This secondary drawing thus became the record of a curated set of citizen ideas, translated through the interpretation and expertise of architecture students. By contrast, the table surface became less and less 'precious' as more and more participants scribbled on it among spilled food as the evening wore on.

The second case study at the 2019 ACSA Stanford conference reproduced the co-drawing table as artifact for an expert audience. The site and subject, here, was the campus typology as an environment of knowledge production. The drawing table, made up of a series of easily re-deployable folding tables (Fig. 


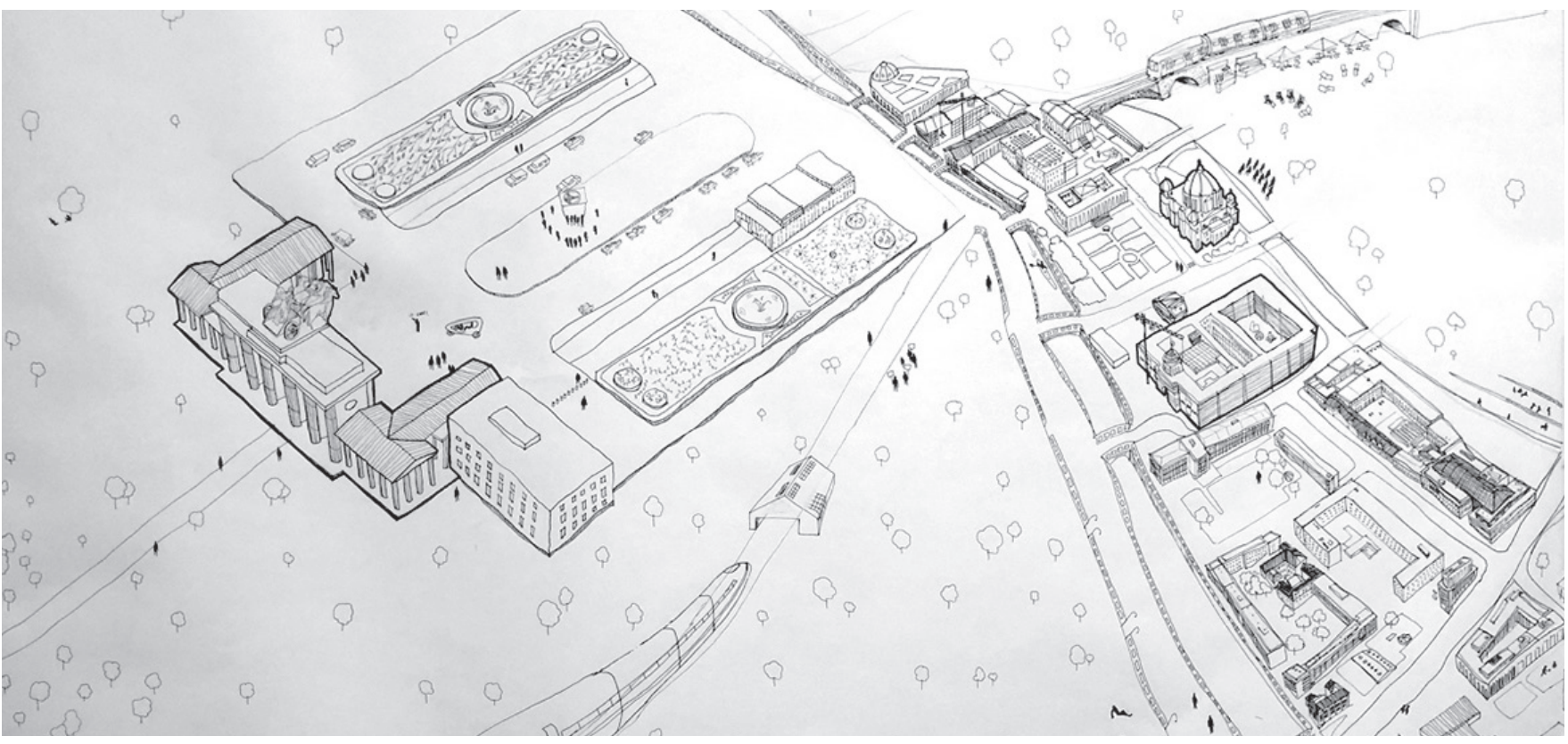

Figure 4: Sample base drawing, Berlin (collaborative drawing by CCA student group)

5), contained plan drawings of the Stanford campus, as well as other iconic American sites of learning, from 19th century schoolhouses to Jefferson's University of Virginia campus. Critiquing the spatial hierarchies of knowledge production/sharing within typical educational typologies, the protocols provided to participants were presented as a set of large dice (Fig. 6), adding a game element to the exchange and the act of drawing collectively. One set contained precedents from relational art and activist projects -strategies for producing more democratic sites of conversation and exchange (Fig. 7). A second set of dice contained suggestions for architectural/spatial conditions that might serve as alternative sites of knowledge exchange. The overall event was designed as a 45-minute design charette/collaboration in which participants engaged each other and the base drawing in a dialog about future, more shared spaces for knowledge exchange in a campus environment.

Counter to the Berlin drawing table event, the Stanford experiment sought to capitalize on the expertise of its audience. Rather than investigating scenarios for a single specific location, the base drawing brought the form of the conference and the Stanford campus into the context of its typological lineage. Represented through abstracted plan drawings of different sites of knowledge production, this base drawing was designed to provide space for new ideas between careful interpretation and playful intervention from a design expert audience. Prioritizing playful multiplicity of ideas, the dice were offered as a catalyst for forward-pointing conversation grounded in specific contemporary discourses regarding the forms and spaces of knowledge exchange, while leveraging strategies rooted in design activism and relational art. Pens for drawing were chosen in a color different from the base drawing, resulting in a clear record of the proposed interventions on the black and white base drawing. Sitting together at a table within a short charette contributed to spontaneous conversations and collaboration (Fig.8), enabled by the fact that the expert audience was familiar with the disciplinary questions and quick workshop formats.

The contrast of the different sites, questions, and audiences in these two experiments offers lessons on the potentials and limitations of co-drawing as a tool of engagement, testing the teaching format, approach, and outcome as a contemporary learning environment that builds hands-on knowledge around public space production. In the design of the artifact, protocol, and event for both, traditional design methods and actions are modified but essential. Architectural and teaching expertise is balanced with ceding some design control to participants, a level of control that needs to be calibrated to the relative expertise offered by participants. The Berlin audience offered expertise on the local environment, its use and significance for inhabitants, while the Stanford audience offered spatial expertise on the possible rethinking of known typologies. Correspondingly, the base drawings for the Berlin drawing table were more pictorial, providing easy relatability, while the Stanford base drawings capitalized on the abstraction of reduced plan drawings to offer a disciplinary canvas for spatial ideas. The respective prompts and protocols for the events bracket a spectrum of how co-drawing can catalyze dialog and record knowledge. The Berlin prompts asked participants to contribute their local experience in and with the space, consciously not asking non-architects to design its future. The Stanford drawing game prompts, by contrast, were designed to catalyze spatial ideas, capitalizing on the disciplinary expertise of that audience. 


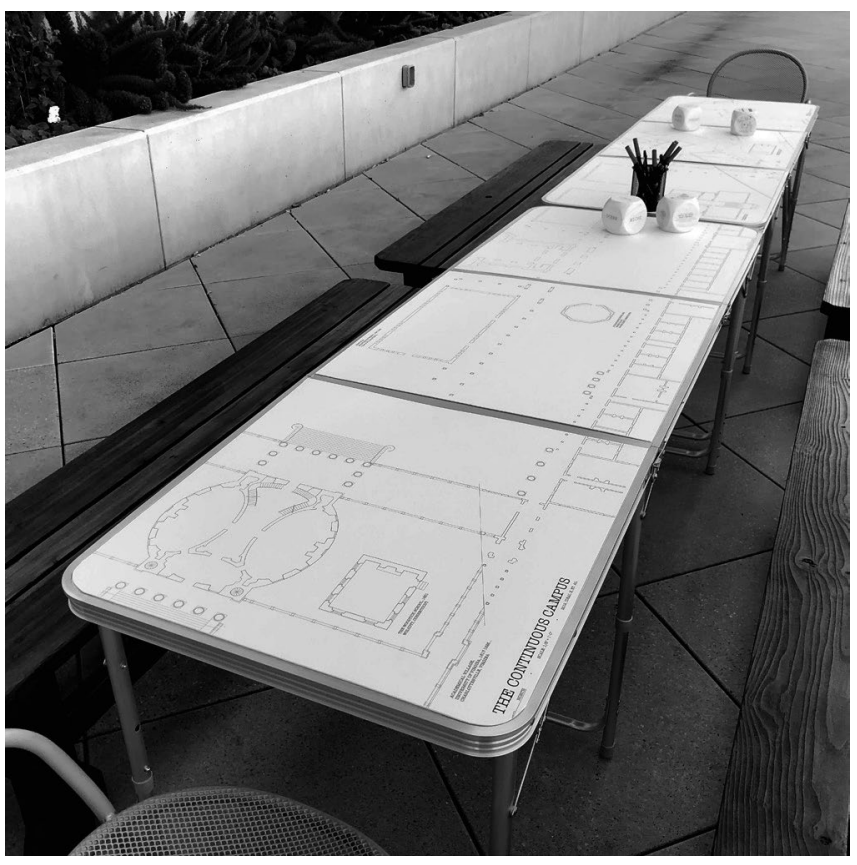

Figure 5. Drawing table, Stanford (photo: Antje Steinmuller)

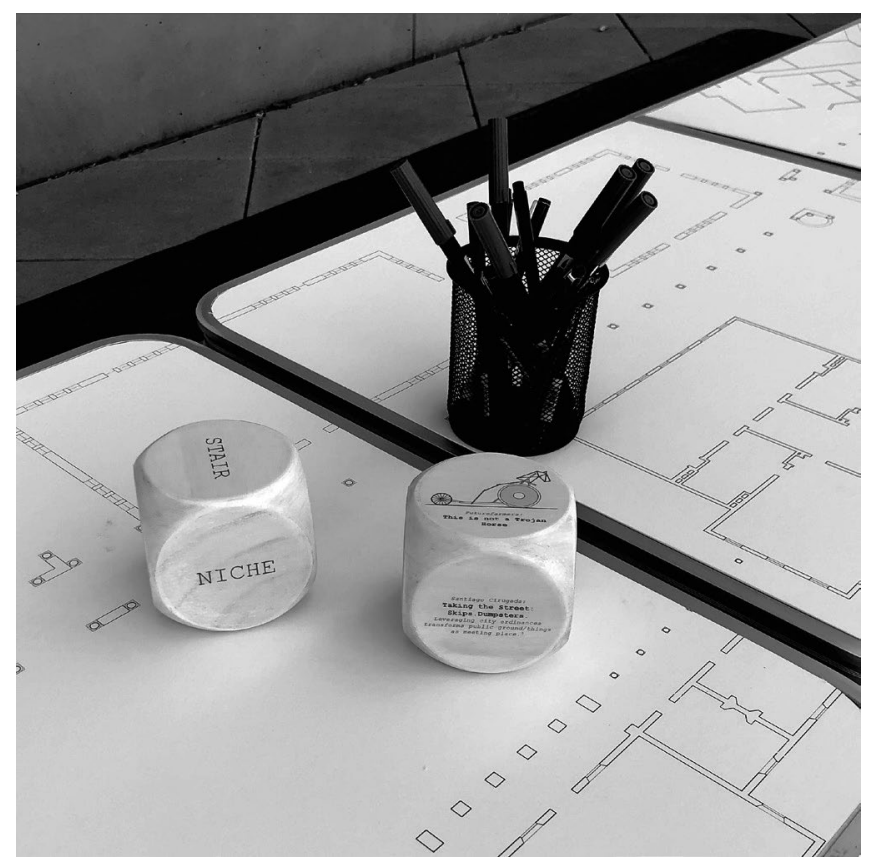

Figure 6. Dice offering protocols for collaborative drawing (photo: Antje Steinmuller)

The potentials of these temporary involvements with a site and project pose questions about what can be catalyzed short-term as much as long-term as a result of co-drawing. These potentials and limitations are examined relative to a conventional design process that might include community engagement. Typical community engagement in the form of



Figure 7. Strategies for the creation of new sites of knowledge exchange (photo: Antje Steinmuller)

architect-led presentations and subsequent discussion, by nature, establish a more hierarchical setting of presenteraudience. Comments are recorded through writing with the resulting record not always visible to participants. The meeting format favors a singular thread of conversation, architects' presentations and consecutive responding comments vs. the multiplicity and simultaneity of ideas. Co-drawing, if introduced early and periodically into a design process, offers a setting for informal and playful engagement of all generations with room for multiple and diverse input, solicited and moderated through architectural expertise -manifest in the design of artifact, protocol, and the choreography of the overall event.

As a teaching methodology, co-drawing presents a more immediate and more complex format for a classroom, class content, and architectural learning through the design of tools for citizen engagement. This challenges students to reflect on the essence of, and place for architectural expertise in today's urban environments. It asks students to move beyond the design of form to that of a process of formation that plays out over time, and positions the architect as an active agent in direct communication with the subject community. While a singular short-term co-drawing event may have limitations in its impact on long-term processes, the format, deployed in a long-term engaged relationship between architect and local citizens, offers new ways of recognizing and recording citizen expertise through events that build community and platforms for dialog. 


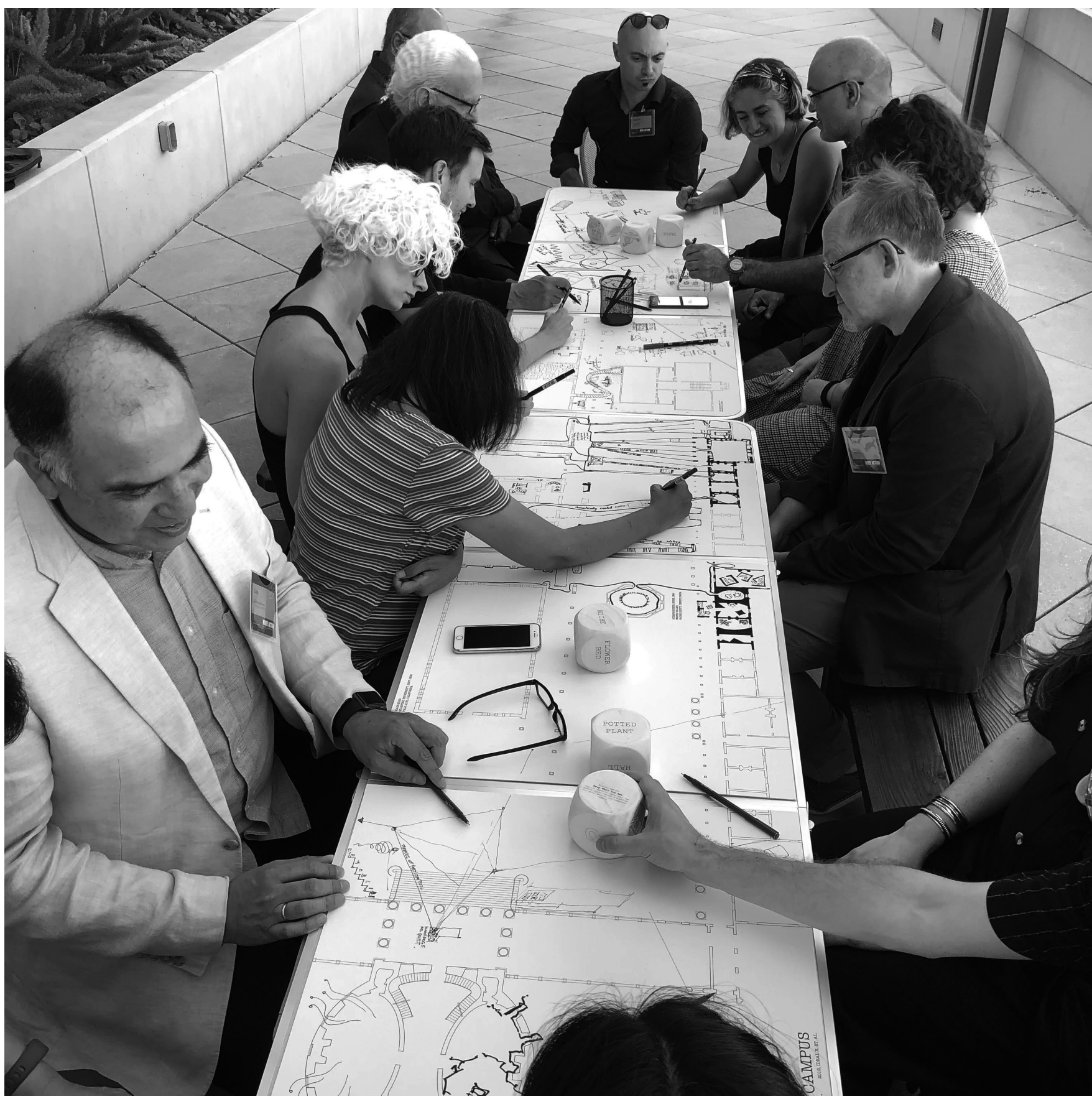

Figure 8. Co-drawing event at the ACSA Stanford conference session, September, 2019 (photo: Antje Steinmuller)

\section{ENDNOTES}

1. Gideon Fink Shapiro, "Spacebusting", Archiweb, accessed January 10, 2019, https://www.archiweb.cz/en/b/spacebuster

2. Nicolas Bourriaud. Relational Aesthetics (Dijon: Les Presses de Réel, 2002), 9.

3. Bourriaud, Relational Aesthetics, 28.

4. see Henri Lefebvre and Donald Nicholson-Smith. The production of space. Vol. 142 (Blackwell: Oxford, 1991).

5. Nishat Awan, Tatjana Schneider, Jeremy Till. "Introduction", in Spatial Agency: Other Ways of Doing Architecture (London/New York: Routledge, 2011), 29.

6. Anthony Giddens. Social Theory and Modern Sociology (Cambridge: Polity, 1984), 220.
7. Awan/Schneider/Till. "Introduction", 32

8. see also Antje Steinmuller and Chris Falliers, "CO-DRAWING - Forms of spatia communication as formats for collective dialogue", paper presented at the 2018 ACSA International Conference, Madrid, Spain. 